and in this sense its proposals are, and certainly should be, "specialist."

The declared intention of Dr Westcott and his colleagues "to demonstrate the general practice answer" is very welcome, and I hope their counter-proposals will share the Court Committee's overriding concern that vested professional interests should not get in the way of effective services to meet the special needs of children. May I give one example of the problems they will face? Education authorities will rightly insist that they are provided with a school health service which shares fully in the rising standards which we all seek. Can those who are unhappy about the report's proposals, in this and other respects, suggest an alternative pattern of services which will avoid perpetuating the present divided services? Experience leads us to believe that such divided services will be divisive: this would be in the interests of no one, least of al children. And that, after all, is what it is all about.

Michael Rogers Principal Clinical Medical Officer
Berkshire Area Health Authority

Reading

\section{Breast conservation in mammary} carcinoma

SIR,-I am surprised that Mr Hermon Taylor (2 April, p 908) is surprised that you did not quote his paper on "sector mastectomy" in your leading article ( 5 March, p 595). After all, neither did you quote the quite excellent account of this procedure in $A$ General System of Surgery by my old friend $\mathrm{Dr}$ Laurence Heister, of the University of Helmstadt, published in 1753 . He particularly commends using a dressing dipped in warm ale and butter. It is becoming increasingly difficult these days to claim a "first" in any field of surgery.

Westminster Medical School London SW 1

\section{Erythema infectiosum: no evidence of teratogenicity}

SIR,-In reporting an epidemic of erythema infectiosum ("slapped cheek" disease) in north Devon" we promised to follow up all the women in our area who were in the first trimester of pregnancy during the epidemic and its incubation period. Ager et $a l^{2}$ followed up seven women who were known to be in the first trimester during the epidemic they recorded and found no evidence of teratogenicity from erythema infectiosum.

In our area the number of pregnancies for this period which ended successfully was 29 . The number of spontaneous abortions was three. There were no abnormalities of a teratogenic nature. Two babies were slightly small for dates and both scored Apgar 5. All the rest were large and healthy and scored Apgar 7 or more. Two had "clicky hips" and one had wide skull sutures: two later had attacks of bronchiolitis and one had a cyanotic attack.

This group compared well with the products of the pregnancies for the same period of the previous year. Then there were 25 successful pregnancies and again three spontaneous abortions. One baby had a mid-thoracic, nonparalytic spina bifida and one suffered deafness as a result of frank maternal rubella during the first trimester. One developed a systolic murmur and one had a convulsion on the third day of life.

Follow-up of 38 of the children who had erythema infectiosum during the epidemic revealed that no fewer than seven of them were atopic, five suffering from asthma and two from eczema. One child developed an unexplained convergent squint a few weeks after the epidemic.

Overall we cannot find any evidence that erythema infectiosum is teratogenic in the same sense as rubella. Indeed, the control group of infants had more abnormalities than those studied. The high incidence of atopy among the children who had the disease presumably reflects the fact that those with a high histamine level in their skin would show the features of erythema infectiosum more vividly.

H E CRAMP

Great Torrington, B D J ARMSTRONG

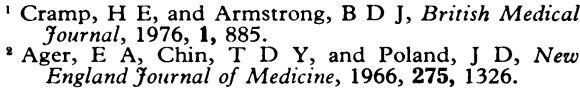
England fournal of Medicine, 1966, 275, 1326.

\section{When to visit}

SIR, - The article on the subject of GP night visiting rates in your "General Practice Observed" series (26 March, p 827), although appearing initially innocuous, carried what was to me an alarming sting in its penultimate paragraph.

"Only on the basis of adequate information can family practitioners develop a consensus about explicit criteria to be used both in 'educating' patients about when to request night calls and in deciding when to visit in response. For these criteria to depend on the idiosyncracies of individual practitioners cannot be a satisfactory state of affairs either for the medical profession or for patients."

To be instructed by a committee when to visit my patients is an imposition I would find hard to bear. The day I am instructed by anyone when I should not visit my patients will be the day I resign from practice.

J M BARRITT

Richmond,

Yorks

Insurance companies' attitude to psychiatric illness

SIR,-Dr J T Hutchinson has written cogently (19 March, p 775) about the unenlightened and stigmatous attitude adopted by certain insurance companies towards patients who have had mild psychiatric disorders and who desire to take out life insurance.

I wish to report briefly on a different, although related, aspect. Recently I have had under treatment three male patients with an age range of 24-44 years who are employed by insurance companies at various clerical and management levels. One suffered from a neurotic depression, another from an obsessional neurosis, and the third from alcoholism. All were treated as outpatients and despite their problems had good employment records. Each-and especially the latter two patientsstressed the punitive attitude of their employers and the comparative lack of confidentiality within their companies regarding employees who seek psychiatric assistance.

These admittedly random observations, when considered in association with those of Dr Hutchinson, suggest a problem of discriminatory attitudes concerning psychiatric disorders, as well as an inability to differentiate the mild from the serious, on the part of some insurance companies.

A Balfour SClare

Department of Psychiatry Duke Street Hospital, Glasgow

\section{Breast size and cancer}

SIR,-With reference to Professor B N Catchpole's letter (19 March, p 776) about breast size and cancer, I wonder whether he has tried relating these to breast-feeding ? It is well known among women that success in breast-feeding is often inversely related to breast size. As one small-busted, amply lactating patient said to me, "I may not have much, but all I've got works. The big ones are all for show." As breast cancer rarely seems to arise in those who have been successful breast-feeders and as these are often the coffee-cup rather than the challenge-cup size, it would seem that, as Professor Catchpole suggests, the size and fat content of breasts may be of more than aesthetic importance.

MARJORIE REID

Winslow,
Buckingham

\section{Medicine in Staffordshire}

SIR,-Having greatly enjoyed Dr D Gibbs's article on medicine in Staffordshire (19 March, p 765) may I add a gloss on the first descriptions of the use of the foxglove in dropsies? It is widely believed that Withering's is the first such account, but his description, ${ }^{1}$ published in the latter half of 1785 , is preceded by at least five others.

In 1780 two essays of Charles Darwin were published posthumously by his father, Erasmus, ${ }^{2}$ and to them was subjoined a note in which were described the histories of nine dropsical patients treated with foxglove. No more was published until February 1785, when the editor of the London Medical fournal reviewed the reports that had reached his notice from physicians at Edinburgh and London. ${ }^{3}$ Subsequently, in a paper read to the Royal College of Physicians of London in March 1785, Erasmus Darwin ${ }^{4}$ described the treatment of six cases and claimed authorship of the note appended to his son's works. That paper was followed by an account by $\mathrm{Sir}$ George Baker, ${ }^{5}$ better known for his observations on lead poisoning, ${ }^{6}$ of the treatment of four cases and a brief history of the uses of the foxglove before that time. Finally John Warren, in a letter to one Dr Simmons in May 1785 , recounted his experience in four cases.

In none of these accounts was Withering's name mentioned, but Withering in the second edition of his botany ${ }^{8}$ gives references which lead one to the other sources. Withering's description of his own case IV $^{1}$ makes it clear that Darwin learnt the use of the foxglove from him and Withering's irritation at Darwin's 1780 publication is evident.

It was Darwin who in 1775 invited Withering to fill Dr Small's place in Birmingham and 
who a year later introduced him into the Lunar Society. Later, however, Darwin seems to have become jealous of Withering's multifarious successes, and their friendship soured. Darwin's failure to mention Withering in eithe of his publications was reprehensible, but the omission of Withering's name from the othe publications was probably due to ignorance of his contribution. Darwin ended his paper to the royal college by saying that digitalis wanted only "the stamp of some great name, to make it current amongst the faculty." Doubtless he hoped that that name would be his own, but posterity has accorded the accolade to its rightful recipient, William Withering.

J K ARonson

Radcliffe Infirmary,

Oxford

1 Withering, W, An Account of the Foxglove and some of its Medical Uses: with Practical Remarks on the

- Darwin, C, Experiments Establishing a Criterion between Mucaginous and Purulent Matter and an Account of the Retrograde Motions of the Absorben $\mathrm{J}$ Jackson, 1780.

London Medical fournal, 1785, 6, 55.

- Darwin, E, Medical Transactions of the Royal College of Physicians of London, 1785, 3, 255.

- Baker, Sir G, Medical Transactions of the Royal College of Physicians of London, 1785, $3,287$.

- Baker, Sir G, Medical Transactions of the Royal College of Physicians of London, 1772, 1, 175.

Warren, J, London Medical fournal, 1785, 6, 145. Withering, W, A Botanical Arrangement of British Plants; including the uses of such species, in medicine, introduction to the study of botany, 2nd edn. Edinintroduction to the study of botany, 2nd edn. EdinRobson, J Balfour and C Elliott, 1787.

\section{Diet and the diabetic}

SIR,-You rightly mention in your leading article on this subject (2 October, p 780) that "the composition of the ideal diet for insulintreated patients is continually debated." The clinician in India and in other developing countries has so far been advocating a diabetic diet consisting of $45-50 \%$ of sugar-free carbohydrates similar to that prescribed for Western diabetics. But experience has taught us that such a diet is not practical in countries where the consumption of carbohydrates by the general population is usually not less than $70-80 \%$ of the total calories. Besides, a diabetic of average means can ill afford a diet composed mostly of proteins and fats.

Since only $8 \%$ of all the diabetic patients in our clinic stuck to the prescribed diet, largely because of the high cost, a study was undertaken to assess the effect of an isocaloric high-carbohydrate diet on (1) the control of hyperglycaemia, (2) the requirement of antidiabetic agents, and (3) the serum lipid abnormalities. A total of 40 patients with diabetes, of the maturity-onset type in 31 and of the juvenile-onset type in 9, were studied, together with 20 aged-matched normal healthy controls. The diabetics were examined clinically and biochemically before and after hyperglycaemia had been controlled

Serum insulin concentrations in $m U / l$ (mean $\pm S D$ ) during $G T T$ in 20 normal subjects and 31 maturityonset diabetics

\begin{tabular}{|c|c|c|c|c|c|}
\hline & & \multicolumn{2}{|c|}{$\begin{array}{l}\text { Standard diet } \\
(50 \% \mathrm{CHO})\end{array}$} & \multicolumn{2}{|c|}{$\begin{array}{c}\text { High-carbohydrate diet } \\
(70 \% \text { CHO })\end{array}$} \\
\hline & & Normals & Diabetics & Normals & Diabetics \\
\hline 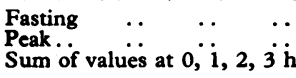 & $\begin{array}{l}. . \\
\ldots\end{array}$ & $\begin{aligned} 18 \cdot 1 & \pm 2 \cdot 6 \\
65 \cdot 6 & \pm 10 \cdot 25 \\
147 \cdot 6 & \pm 18 \cdot 18\end{aligned}$ & $\begin{array}{r}28 \cdot 8 \pm 10 \cdot 36 \\
90 \cdot 85 \pm 12 \cdot 23 \\
295 \cdot 0 \pm 53 \cdot 54\end{array}$ & $\begin{array}{c}17 \cdot 8 \pm 2 \cdot 23 \\
60 \cdot 4 \pm 6 \cdot 0 \\
139 \cdot 2 \pm 12 \cdot 53\end{array}$ & $\begin{aligned} 22 \cdot 35 & \pm 1 \cdot 59 \\
87 \cdot 7 & \pm 6 \cdot 25 \\
263 \cdot 55 & \pm 12 \cdot 62\end{aligned}$ \\
\hline
\end{tabular}

on the standard diabetic diet containing $50 \%$ carbohydrate. They were then put on an isocaloric high-carbohydrate diet containing $70 \%$ carbohydrate for a period of four weeks and the tests were repeated.

In the normal subjects the fasting and 2-h blood glucose values and the sum of the glucose values in the glucose tolerance test (GTT) showed no significant change on the high-carbohydrate diet as compared with the standard diabetic diet $(P>0.05)$. Insulin kinetics also did not alter in these subjects as shown by the fasting, peak, and sum of insulin values after the GTT $(P>0.05)$ (see table). Serum cholesterol, triglyceride, and free fatty acid concentrations also showed no significant change.

In the maturity-onset group of diabetics the requirement of oral hypoglycaemic agents was increased in only one patient, who needed $2.5 \mathrm{mg}$ more of glibenclamide daily when put on the high-carbohydrate diet, while in four the requirement was decreased. The fasting and $2-h$ glucose values and the sum of the in 19 patients, were unchanged in 8 , and showed some deterioration in 4 . In the juvenile-onset group the insulin requiremen decreased in five patients and remained unchanged in the rest. Other workers in India such as Vishwanathan ${ }^{1}$ and Patel et al, ${ }^{2}$ have reported similar experiences.

We therefore feel that hyperglycaemia can be controlled with a sugar-free isocaloric highcarbohydrate diet in the majority of diabetic patients. Besides, it is cheap and practical.

HaRi Vaishnava S N A Rizv

Department of Medicine P D Gulat Maulana Azad Medical College and Associated Hospitals, New Delhi, India

1. Viswanathan, M, Madhumeha, 1968, 8, 5 .
Patel, J C, et al, in Proceedings of the World Congress
on Diabetes in the Tropics, 1966, p 527 . Bombay,
Diabetic Association of India, 1968.

\section{Alcohol and road accidents}

SIR,-Your leading article on this subject (12 March, p 665) calls for information about the blood alcohol concentrations in victims of road accidents. As you say, the taking of blood samples for this purpose from drivers would lead to considerable legal and ethical difficulties, but this does not seem to apply in our experience to breath sampling. For the pas nine months breath samples have been taken for diagnostic purposes with an Alcolmeter (made by Lion Laboratories Ltd, Pearl Street, Cardiff) from unconscious or drowsy patients, including victims of road or other accidents, admitted to the accident and emergency department of this hospital.

The Alcolmeter has the useful property of aspirating its sample, so that unconerious patients present no difficulty. The sample is glucose values in the GTT improved markedly

taken from a nostril at the end of expiration which may be slightly accentuated by pressing on the chest. Conscious patients can easily be persuaded to blow through a mouthpiece attached to the instrument.

Although breath-alcohol analysis does no give such accurate and precise results as blood analysis $^{2}$ it is quite good enough for clinical purposes and has been found to be of considerable value in differential diagnosis. In one case a preliminary diagnosis of alcoholic coma was ruled out by a finding of a blood alcohol concentration (BAC) of only $40 \mathrm{mg} / 100 \mathrm{ml}$; further investigation showed that other drugs were involved. In other cases patients who claimed to have drunk very little alcohol were found to have BACs well over $100 \mathrm{mg}$, and in one road accident victim the level reached $200 \mathrm{mg}$. The information obtained in this way is used for clinical purposes only, but it is recorded in the patient's notes. If other accident and emergency departments adopted the same policy, the information you require would soon become available.

T P WELCH

B M WRIGHT

Northwick Park Hospital and

Clinical Research Centre,

Medical Research Council, Annual Report, 1972-3, pp 104-105.

right, B M, et al, Medicine, Science and the Law $1975,15,205$

\section{Potassium in heart failure}

SIR,-Your leading article (19 February, p 469) states that potassium supplements are mandatory in some categories of patients with heart failure, one of these being "elderly patients on diuretics alone (because their intake is poor)." If, however, indiscriminate use of potassium supplements is to be avoided, the statement requires a positive answer to the following three questions in order to gain validity:

(1) Can potassium depletion be identified by generally available methods ? Your article correctly points out that many patients in heart failure are depleted of total exchangeable potassium despite normal plasma concentrations and, one might add, the correlation between plasma potassium concentration and total body potassium is poor. ${ }^{1}$ The answer to the first question is negative.

(2) Is correction of potassium depletion, once diagnosed, necessary? Many authors have failed to detect adverse symptoms or signs ascribable to potassium deficiency in patients on diuretics. ${ }^{23}$ The answer to the second question is equivocal at best.

(3) Are potassium supplements a reliable way of preventing or correcting potassium depletion ? Down et al $^{4}$ gave a negative answer to this question and Davidson et $a l^{5}$ found no relation between the dose of potassium supplements and either the plasma potassium concentration or total body potassium.

A study of 489 geriatric outpatients ${ }^{6}$ demonstrated that in 178 patients on diuretics potassium supplements did not influence the mean serum potassium concentration in either sex. Another important finding was that mean serum potassium in men on diuretics was only insignificantly decreased compared with men not on diuretics, whereas mean serum potassium in women on diuretics was significantly lower than in women not on diuretics. Only one of 44 men on diuretics had a reduced serum potassium concentration $(3.3 \mathrm{mmol} / \mathrm{l})$, 